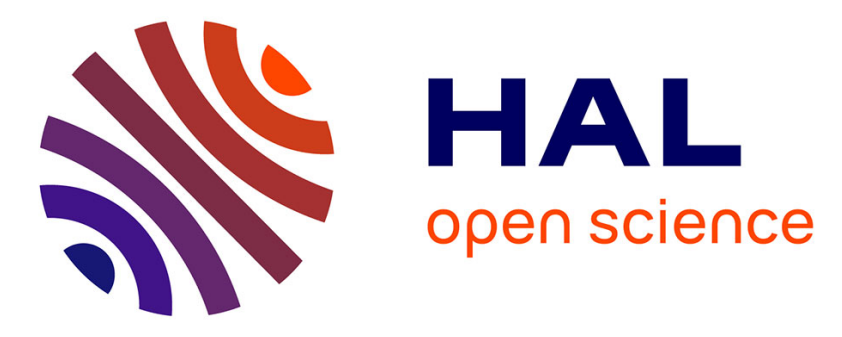

\title{
Early discharge in selected patients with low-grade renal trauma
}

Lucas Freton, Lucie-Marie Scailteux, Marine Hutin, Jonathan Olivier, Quentin Langouet, Marina Ruggiero, Ines Dominique, Clémentine Millet, Sébastien Bergerat, Paul Panayatopoulos, et al.

\section{To cite this version:}

Lucas Freton, Lucie-Marie Scailteux, Marine Hutin, Jonathan Olivier, Quentin Langouet, et al.. Early discharge in selected patients with low-grade renal trauma. World Journal of Urology, 2020, 38 (4), pp.1009-1015. 10.1007/s00345-019-02855-y . hal-02180025

\section{HAL Id: hal-02180025 \\ https://hal-univ-rennes1.archives-ouvertes.fr/hal-02180025}

Submitted on 30 Mar 2020

HAL is a multi-disciplinary open access archive for the deposit and dissemination of scientific research documents, whether they are published or not. The documents may come from teaching and research institutions in France or abroad, or from public or private research centers.
L'archive ouverte pluridisciplinaire HAL, est destinée au dépôt et à la diffusion de documents scientifiques de niveau recherche, publiés ou non, émanant des établissements d'enseignement et de recherche français ou étrangers, des laboratoires publics ou privés. 


\section{EARLY DISCHARGE IN SELECTED PATIENTS WITH LOW-GRADE RENAL TRAUMA}

Lucas FRETON ${ }^{1}$, Lucie-Marie SCAILTEUX ${ }^{2}$, Marine HUTIN ${ }^{3}$, Jonathan OLIVIER ${ }^{4}$, Quentin LANGOUET ${ }^{5}$, Marina RUGGIERO ${ }^{6}$, Ines DOMINIQUE ${ }^{7}$, Clémentine MILLET $^{8}$, Sébastien BERGERAT ${ }^{9}$, Paul PANAYATOPOULOS ${ }^{10}$, Reem BETARI ${ }^{11}$, Xavier MATILLON $^{7}$, Ala CHEBBI $^{12}$, Thomas CAES ${ }^{4}$, Pierre-Marie PATARD ${ }^{13}$, Nicolas SZABLA $^{14}$, Nicolas BRICHART ${ }^{15}$, Axelle BOEHM ${ }^{5}$, Laura SABOURIN ${ }^{8}$, Kerem GULERYUZ ${ }^{14}$, Charles DARIANE ${ }^{16}$, Cédric LEBACLE ${ }^{6}$, Jérome RIZK ${ }^{4}$, Alexandre GRYN $^{13}$, François-Xavier MADEC ${ }^{17}$, François-Xavier NOUHAUD ${ }^{12}$, Xavier ROD ${ }^{17}$, Emmanuel OGER ${ }^{2}$, Gaelle FIARD ${ }^{18}$, Karim BENSALAH ${ }^{1}$, Benjamin PRADERE $^{5}$, Benoit PEYRONNET $^{1}$ for the TRAUMAFUF collaborative group

1: University of Rennes, Urology, Rennes, France

2: Univ Rennes, CHU Rennes, REPERES [(Recherche en Pharmaco-épidémiologie et Recours aux Soins)] - EA 7449, F-35000 Rennes, France

3. University of Montpellier, Urology, Montpellier, France

4. University of Lille, Urology, Lille, France

5. University of Tours, Urology, Tours, France

6. University of Paris Sud, CHU Bicetre, Urology, Paris, France

7. University of Lyon, Urology, Lyon, France

8. University of Clermont-Ferrand, Urology, Clermont-Ferrand, France

9. University of Strasbourg, Urology, Strasbourg, France

10. University of Angers, Urology, Angers, France

11. University of Amiens, Urology, Amiens, France

12. University of Rouen, Urology, Rouen, France

13. University of Toulouse, Urology, Toulouse, France

14. University of Caen, Urology, Caen, France

15. University of Orléans, Urology, Orléans, France

16. University of Paris Descartes, Urology, Paris, France

17. University of Nantes, Urology, Nantes, France

18. University of Grenoble, Urology, Grenoble, France

\section{Corresponding Author:}

Lucas Freton 
Service d'urologie

Hopital Pontchaillou

2 rue Henri Le Guilloux

35000 Rennes, France

mail: lucas.freton@gmail.com

Abstract word count: 249

Text word count: 2359

Keywords: renal trauma ; outpatient ; management ; complication ; propensity score

\begin{abstract}
Introduction

The aim of this study was to assess whether early discharge could be non-inferior to inpatient management in selected patients with low-grade renal trauma (AAST grades 1 to 3 ).
\end{abstract}

\title{
Materials and methods
}

A retrospective national multicenter study was conducted including all patients who presented with renal trauma at 17 hospitals between 2005 and 2015. Exclusion criteria were iatrogenic and AAST grades 4 and 5, non-conservative initial management, $\mathrm{Hb}<10 \mathrm{~g} / \mathrm{dl}$ or transfusion within the first 24 hours, and patients with concomitant injuries. Patients were divided in two groups according to the length stay: $\leq 48$ hours (early discharge), and $>48$ hours (inpatient). The primary outcome was "Intervention" defined as any interventional procedure needed within the first 30 days. A Stabilized Inverse Probability of Treatment Weighting (SIPTW) propensity score based binary response model was used to estimate risk difference.

\section{Results}

Out of 1764 patients with renal trauma, 311 were included in the analysis (44 in the early discharge and 267 in the inpatient group). In the early discharge group, only one patient required an intervention within the first 30 days vs. 10 in the inpatient group (3.7\% vs. 5.2\%; $\mathrm{p}=0.99$ ). Adjusted analysis using SIPTW propensity score showed a risk difference of $-2.8 \%$ $[-9.3 \%$ to $+3.7 \%]$ of "interventions" between the two groups meeting the non-inferiority criteria. 


\section{Conclusion}

In a highly selected cohort, early discharge management of low-grade renal trauma was not associated with an increased risk of early "intervention" compared to inpatient management. Further prospective randomized controlled trials are needed to confirm these findings. 


\section{Introduction}

Renal trauma is the most common genitourinary trauma, seen in up to $5 \%$ of all trauma cases and in $10 \%$ of all abdominal trauma cases (1). Over the past few decades, the emergence of computerized tomography (CT) scan and angio-embolization has revolutionized the management of renal trauma and has favored a paradigm shift from routine surgical exploration towards an increasing role of non-operative management (2). The safety of a conservative management for the vast majority of renal trauma has been extensively demonstrated and the conservative approach is now considered the gold standard in most cases $(3,4)$. However, current guidelines support inpatient management of all patients with renal trauma, including those with low-grade trauma $(1,5)$. One could question the interest of keeping patients in the hospital when no care is provided as it is the case for most low-grade renal trauma. Outpatient management of this patient population may theoretically be more cost-effective and may decrease the risk of complications such as nosocomial infections or venous thromboembolism (6). While outpatient management is gaining wider and wider acceptance for many surgical procedures and is largely promoted by health authorities (7), its role has never been explored for renal trauma to date.

The aim of this study was to assess whether early discharge could be non-inferior to inpatient management in selected patients with low-grade renal trauma (American Association for the Surgery of Trauma (AAST) grades 1 to 3 ). 


\section{Materials and methods}

\section{$\underline{\text { Study design }}$}

The TRAUMAFUF project was a retrospective national multicenter study including all patients with renal trauma who presented at 17 French hospitals between 2005 and 2015. This research project was not funded and relied exclusively upon the commitment of French urologists in training, members of the "Association Francaise des Urologues en Formation" (AFUF). The exclusion criteria were iatrogenic (post biopsy or surgical procedure) and penetrating renal trauma, unknown grade or high-grade (AAST grades 4 and 5) renal trauma, non-conservative initial management (i.e. upfront surgery or embolization), hemoglobin $<10$ $\mathrm{g} / \mathrm{dl}$ or blood transfusion within the first 24 hours after admission, and concomitant visceral and/or bone injuries. Patients were divided in two groups according to the length of hospital stay: $\leq 48$ hours (early discharge group) and $>48$ hours (inpatient group). The following data were collected for each patient: age, gender, AAST grade, renal trauma side, type of initial imaging, active bleeding on initial imaging, angio-embolization for active bleeding on initial imaging, gross hematuria, initial hemodynamic status, length of stay, hemoglobin level at initial presentation, re-imaging and length of follow-up. The study was approved by the local ethics committee and was conducted following the principles of the Helsinki declaration.

\section{$\underline{\text { Renal trauma management }}$}

Due to the retrospective and multicenter study design, the management of renal trauma was not standardized throughout the study population. As per national and international guidelines, inpatient management was the standard of care in all participating centers over the study period and early discharge occurred in many cases in patients actively refusing hospital admission or prolonged hospital stay and at their request, often against medical advice. However, at all participating institutions, those patients were offered follow-up visits and their follow-up data were recorded and analyzed for the purpose of the present report.

\section{$\underline{\text { Outcomes of interest }}$}

The primary endpoint was "Intervention" defined as any interventional radiology (IR) or surgical procedure needed within the first 30 days after initial presentation. The secondary outcomes of interest were readmission, nephrectomy rate, blood transfusion within the first 30 days and death due to renal trauma. 


\section{$\underline{\text { Statistical analyses }}$}

All the statistical analyses were computed by the statistics team of the hospital center. Means and standard deviations were reported for continuous variables, and proportions for categorical variables. The main hypothesis was to test the non-inferiority between early discharge and inpatient management in terms of risk of interventional radiology and/or surgical procedure within the first 30 days after the trauma. We anticipated around $5 \%$ of surgery or radio-embolization among the inpatient group and fixed a non-inferiority margin of 4\%. A weighted (Stabilized Inverse Probability of Treatment Weighting, SIPTW) propensity score-based log binomial regression model was used to calculate a risk difference along with 95\% confidence interval between the inpatient group (reference group) and the early discharge group. The predicted probability of inpatient management or early discharge given baseline variables (age, gender, AAST grade and gross hematuria at initial presentation) was calculated using a logistic regression model. The degree to which the propensity score was appropriately specified was ascertained through evaluation of common support, defined by overlapping distributions of propensity scores between exposure groups, and standardized differences after weighting. Comparisons between groups were performed using the $\chi^{2}$ test or Fisher's exact test as appropriate for discrete variables, and Mann-Whitney test for continuous variables. All analyses were conducted using the SAS statistical package (version 9.4; SAS Institute, Cary, NC, USA). 


\section{Results}

\section{$\underline{\text { Patients' characteristics }}$}

Out of 1764 patients with renal trauma, 311 were included for analyses: 44 in the early discharge group and 267 in the inpatient group. 1453 patients were excluded (see figure 1): 620 patients had an unknown grade or high-grade trauma, 242 a non-conservative initial management, 823 a visceral and/or bone injury, and 781 a transfusion or hemoglobin $<10 \mathrm{~g} / \mathrm{dl}$ at initial presentation. The patients' characteristics are summarized in table 1. The median age, gender, and proportions of active bleeding on initial CT, initial hemodynamic instability, and gross hematuria at initial presentation were similar between both groups. Conversely, the AAST grades were significantly higher in the inpatient group: there were $70.5 \%$ grade 1 renal trauma in the early discharge group vs. $28.8 \%$ in the inpatient group, $25.0 \%$ vs. $28.1 \%$ of grade 2 renal trauma and $4.6 \%$ vs. $43.1 \%$ of grade 3 renal trauma $(\mathrm{p}<0.0001)$. Hospital stays were significantly shorter in the early discharge group (median 2 days vs. 6 days; $p<0.0001$ ). There was a higher rate of re-imaging in the inpatient group ( $89.2 \%$ vs $44.4 \%$; $<<0.0001)$. Median follow-up was 44 and 89 days in the early discharge and inpatient groups respectively. Nine (20.5\%) and $31(11.6 \%)$ patients were lost to follow-up before the 30 days timepoint in the early discharge and inpatient groups respectively $(\mathrm{p}=0.10)$. After propensityscore weighting, the two groups were almost thoroughly balanced with standardized difference very slightly outside the limits $(-0.12 ;+0.13)$, including a better distribution of AAST grades (see supplementary table 1).

\section{Outcomes in the early discharge vs. inpatient group}

The main outcome status was available for 220 patients $(70,7 \%): 28(63,6 \%)$ in the early discharge group and $192(71,9 \%)$ in the inpatient group. The rates of interventions were comparable in both groups: 1 in the early discharge group and 10 in the inpatient group $(3.7 \%$ vs. $5.2 \%$; $=0.99$; table 2 ). There were no statistically significant differences between the two groups in terms of death from trauma ( 0 vs. $0.5 \%$; $=0.99)$ of nephrectomy $(0$ vs. $0 \% ; p=N A)$ and of blood transfusion ( $0 \%$ vs. $0 \% ; \mathrm{p}=\mathrm{NA}$ ). The readmission rates were also similar in the two groups ( $3.7 \%$ vs. $2.6 \%$; $=0.75$ ). The patient who died was a 68 year-old male patients with medical history of congestive heart failure who was admitted for grade 2 renal trauma after a fall in his bathtub. He experienced a secondary gross hematuria at day 10 likely due to a renal pseudoaneurysm and died of decompensated heart failure. 


\section{$\underline{\text { Weighted analyses }}$}

SIPTW regression model was run on 310 patients without missing data on the chosen baseline variables (see supplementary table 1 for patients' characteristics after propensity score weighting). The model showed a risk difference of $-2.8 \%[-9.3 \%$ to $+3.7 \%]$ of surgical or interventional radiology procedures ("interventions") between the two groups meeting the non-inferiority criteria $(<4 \%)$ for early discharge vs. inpatient management. Due to the very small number of events and inherent lack of statistical power, propensity score weighted analyzes could not be performed for the other outcomes but the scarcity of these outcomes makes an influence of early discharge versus inpatient management on their occurrence very unlikely. 


\section{Discussion}

Current guidelines support inpatient management of all patients with renal trauma, including those with low-grade trauma even though this patient population is not addressed specifically $(1,5)$. However, those recommendations are supported by scant, not to say a total absence of evidence. To our knowledge, indeed, while outpatient management is gaining wider and wider acceptance for many surgical procedures and is largely promoted by health authorities (7), its role has never been explored for renal trauma to date. Various reasons could explain this surprising observation but the most likely is simply that renal trauma, and abdominal trauma in general, is a field where very little financial effort has been done to bring high level of evidence studies, either by health authorities or the industry. Hence, despite being a highly prevalent life-threatening condition, a great part of renal trauma management is still driven by empiricism and dogma. The TRAUMAFUF project, from which the present analyses is drawn, is a purely spontaneous initiative from a group of French urologists in training from all over the country. The very heart of this TRAUMAFUF project is to try, through a "handcrafted" collaborative effort (i.e. with no financial means), to collect a large amount of individual renal trauma data from most academic departments of urology in the country to shed light on issues of renal trauma management yet to be addressed. In what is, to our knowledge, the first study to explore early discharge for patients with low-grade renal trauma, we found that this approach was safe with no increased risk of surgical or interventional radiology procedures, death from trauma, blood transfusions or readmission.

The paradigm of blunt abdominal trauma management has changed over the past three decades and conservative management has become the standard of care for renal trauma as for other solid intra-abdominal organs (2,3,8-11). Non-operative management has been largely evaluated in patients with high-grade renal trauma and current literature suggests low rates of delayed intervention and conservative management failures in this population (12-13). One could then hypothesize that grade 1 to 3 renal trauma would carry an even smaller risk of delayed intervention or conservative management failures. The small number of secondary interventions and complications we observed in both groups confirms, in the largest cohort to date, data from the few studies available on conservative management of grade 3 renal trauma $(14,15)$. This could be per se regarded as an incentive to perform outpatient management in those cases as the risk of readmission and secondary interventions in these low-grade traumas 
appear to be minimal. However, interpretation regarding grade 3 renal trauma should be cautious owing to their very limited number in the early discharge group $(n=2)$.

Several dogmas that have for long guided the management of renal trauma have been challenged over the past few years. While current international guidelines still recommend bed-rest as part of the conservative management of renal trauma, several studies have suggested that early mobilization could be safe for patients with blunt solid organ injuries including two series addressing this issue specifically in patients with renal trauma (16-20). The latest of this study also suggested that early mobilization could instead be beneficial and would favor enhanced recovery (20). Similarly, the use of routine follow-up imaging, another argument to keep patients hospitalized, have progressively declined in the light of increasing evidence of its poor yield in asymptomatic patients (21-22). One could then question the role of hospitalization when only observation is implemented and the likelihood of complications and delayed interventions are very low and predictable, as discussed above.

It is important to stress that early discharges in the present series were the results of individual physicians or patients' initiatives as opposed to the application of a standardized management protocol. The encouraging outcomes observed herein could then certainly be further improved by implementing structured patients' information and education policies at the time of hospital discharge about possible complications and symptoms that should prompt reaching out their care providers. The implementation of formal care pathway and management protocol involving primary care providers may also contribute to improve outcomes of lowgrade renal trauma management. Our study might help clinicians and urological associations to propose early discharge protocol for low-grade isolated renal trauma. Even though it is essential to elucidate deeper economic implications, our study was not designed to make cost analyses comparing early discharge to hospitalized patients.

Our study has several limitations that should be acknowledged. Firstly, it has the biases inherent to its retrospective design. The lack of randomization and strong selection bias especially could be regarded as important flaws as a significant proportion of the patients in the early discharge group were patients who actively refused inpatient management and one may hypothesize that those patients were more likely to be non-compliant with follow-up. Also, limitation is the heterogeneity of management between each center could have heavily influenced study outcomes. Another obvious drawback was the significant differences in 
baseline characteristics between both groups, especially the higher grades of renal trauma in the inpatient group. We tried to balance this bias by conducting the analyses in a subgroup of patients as homogeneous as possible (i.e. exclusion of patients with non-conservative initial management, hemoglobin $<10 \mathrm{~g} / \mathrm{dl}$ or blood transfusion within the first 24 hours after admission, and concomitant visceral and/or bone injuries) and by performing propensity-score weighted analyses. The exclusion of patients who underwent blood transfusion within the first 24 hours might be a matter of debate because, by definition, having to look after the patients for the first 24 hours to see whether they require transfusion or not precludes outpatient management. The relatively small sample size and inherent lack of statistical power prevented us performing adjusted analyses for the secondary outcomes. Our early discharge group did not strictly fulfill the definition of outpatient but this answered to the statistical need of having a sufficient sample size in each group which would not have been doable with a more stringent threshold for length of stay. We did not censor patients with event before landmark (1 month) from analyses but the ten events in the "inpatient" group occurred within the first month. The very limited number of patients with grade 3 renal trauma $(n=2)$ does not allow to draw any conclusion on the applicability of early discharge in this patients' population. The rate of re-imaging was high but this was in line with recommendations from national guidelines over the study period. In summary, in view of these drawbacks, this study should only be regarded as a preliminary rationale to build prospective protocol aiming to properly assess the possible role of outpatient management of low-grade renal trauma. 


\section{Conclusion}

In this multicenter study, early discharge of selected low-grade renal trauma was not associated with an increased risk of intervention compared to inpatient management. The rate of complications and secondary interventional radiology or surgical procedures was overall very low in both groups also supporting the idea that prolonged hospitalization might not be necessary in this patients' population. The limited number of grade 3 renal trauma in the early discharge group prevent to draw any conclusion in this patients' population. Further prospective randomized controlled trials are needed to confirm these findings.

\section{Author's Contribution :}

Lucas FRETON : Data collection, Data analyses, Manuscript writing

Lucie-Marie SCAILTEUX : Data analyses

Marine HUTIN : Data collection

Jonathan OLIVIER : Data collection

Quentin LANGOUET : Data collection

Marina RUGGIERO : Data collection

Ines DOMINIQUE : Data collection

Clémentine MILLET : Data collection

Sébastien BERGERAT : Data collection

Paul PANAYATOPOULOS : Project development

Reem BETARI : Data collection

Xavier MATILLON : Project development

Ala CHEBBI : Data collection

Thomas CAES : Data collection

Pierre-Marie PATARD : Data collection

Nicolas SZABLA : Data collection

Nicolas BRICHART : Data collection

Axelle BOEHM : Data collection

Laura SABOURIN : Data collection

Kerem GULERYUZ : Data collection

Charles DARIANE : Project development

Cédric LEBACLE : Project development, Manuscript editing

Jérome RIZK : Data collection

Alexandre GRYN : Data collection

François-Xavier MADEC : Data collection

François-Xavier NOUHAUD : Data collection

Xavier ROD : Data collection

Emmanuel OGER : Data analyses

Gaelle FIARD : Project development, Manuscript editing

Karim BENSALAH : Manuscript editing

Benjamin PRADERE : Project development, Data management

Benoit PEYRONNET : Project development, Data management, Data analyses, Manuscript editing 


\section{Disclosure of potential conflicts of interest}

The authors declare that they have no conflict of interest.

Ethical approval: All procedures performed in studies involving human participants were in accordance with the ethical standards of each institutional research committee and with the 1964 Helsinki declaration and its later amendments or comparable ethical standards.

Informed consent: Informed consent was obtained from all individual participants included in the study.

\section{References :}

1. N.D. Kitrey (Chair), N. Djakovic, F.E. Kuehhas, N. Lumen, E. Serafetinidis, D.M. Sharma. EAU Guidelines. Urological Trauma Edn. presented at the EAU Annual Congress

Copenhagen 2018. ISBN 978-94-92671-04-2 http://uroweb.org/guideline/urological-trauma/ Accessed 15 june 2019

2. Matthews, L. A., and J. P. Spirnak. "The Nonoperative Approach to Major Blunt Renal Trauma." Seminars in Urology 13, no. 1 (February 1995): 77-82.

3. Keihani, Sorena, Yizhe Xu, Angela P. Presson, James M. Hotaling, Raminder Nirula, Joshua Piotrowski, Christopher M. Dodgion, et al. "Contemporary Management of HighGrade Renal Trauma: Results from the American Association for the Surgery of Trauma Genitourinary Trauma Study.” The Journal of Trauma and Acute Care Surgery 84, no. 3 (March 2018): 418-25. https://doi.org/10.1097/TA.0000000000001796.

4. Sujenthiran, Arunan, Pieter Jan Elshout, Erik Veskimae, Steven MacLennan, Yuhong Yuan, Efraim Serafetinidis, Davendra M. Sharma, et al. "Is Nonoperative Management the Best First-Line Option for High-Grade Renal Trauma? A Systematic Review." European Urology Focus, May 29, 2017. https://doi.org/10.1016/j.euf.2017.04.011.

5. Morey, Allen F., Steve Brandes, Daniel David Dugi, John H. Armstrong, Benjamin N. Breyer, Joshua A. Broghammer, Bradley A. Erickson, et al. "Urotrauma: AUA Guideline." The Journal of Urology 192, no. 2 (August 2014): 327-35. https://doi.org/10.1016/j.juro.2014.05.004.

6. Mahajerin, Arash, Brian R. Branchford, Ernest K. Amankwah, Leslie Raffini, Elizabeth Chalmers, C. Heleen van Ommen, and Neil A. Goldenberg. "Hospital-Associated Venous Thromboembolism in Pediatrics: A Systematic Review and Meta-Analysis of Risk Factors and Risk-Assessment Models." Haematologica 100, no. 8 (August 2015): 1045-50. https://doi.org/10.3324/haematol.2015.123455.

7. Instruction DGOS/R3 no 2010-457 du 27 décembre 2010 relative à la chirurgie ambulatoire : perspectives de développement et démarche de gestion du risque. NOR : ETSH1033647J ; https://solidarites-sante.gouv.fr/fichiers/bo/2011/11-01/ste_20110001_0100_0114.pdf Accessed 15 june 2019 
8. Cirocchi, Roberto, Carlo Boselli, Alessia Corsi, Eriberto Farinella, Chiara Listorti, Stefano Trastulli, Claudio Renzi, et al. "Is Non-Operative Management Safe and Effective for All Splenic Blunt Trauma? A Systematic Review." Critical Care 17, no. 5 (September 3, 2013): R185. https://doi.org/10.1186/cc12868.

9. Soo, Kwan-Ming, Tsung-Ying Lin, Chao-Wen Chen, Yen-Ko Lin, Liang-Chi Kuo, JawYuan Wang, Wei-Che Lee, and Hsing-Lin Lin. "More Becomes Less: Management Strategy Has Definitely Changed over the Past Decade of Splenic Injury--a Nationwide PopulationBased Study.” BioMed Research International 2015 (2015): 124969. https://doi.org/10.1155/2015/124969.

10. Kozar, Rosemary A., and Michelle K. McNutt. "Management of Adult Blunt Hepatic Trauma." Current Opinion in Critical Care 16, no. 6 (December 2010): 596. https://doi.org/10.1097/MCC.0b013e32833f5cd5.

11. Swift, C., and Jeff Garner. "Non-Operative Management of Liver Trauma." Journal of the Royal Army Medical Corps 158, no. 2 (June 1, 2012): 85-95. https://doi.org/10.1136/jramc158-02-04.

12. Wilden, Gwendolyn M. van der, George C. Velmahos, D’Andrea K. Joseph, Lenworth Jacobs, M. George Debusk, Charles A. Adams, Ronald Gross, et al. "Successful Nonoperative Management of the Most Severe Blunt Renal Injuries: A Multicenter Study of the Research Consortium of New England Centers for Trauma." JAMA Surgery 148, no. 10 (October 2013): 924-31. https://doi.org/10.1001/jamasurg.2013.2747.

13. Hampson, Lindsay A., Kushan D. Radadia, Anobel Y. Odisho, Jack W. McAninch, and Benjamin N. Breyer. "Conservative Management of High-Grade Renal Trauma Does Not Lead to Prolonged Hospital Stay.” Urology 115 (May 2018): 92-95.

https://doi.org/10.1016/j.urology.2017.11.018.

14. Winters, Brian, Hunter Wessells, and Bryan B. Voelzke. "Readmission After Treatment of Grade 3 and 4 Renal Injuries At A Level 1 Trauma Center: Statewide Assessment Using The Comprehensive Hospital Abstract Reporting System." The Journal of Trauma and Acute Care Surgery 80, no. 3 (March 2016): 466-71. https://doi.org/10.1097/TA.0000000000000948

15. Thall, E. H., N. N. Stone, D. L. Cheng, E. L. Cohen, E. M. Fine, I. Leventhal, and R. A. Aldoroty. "Conservative Management of Penetrating and Blunt Type III Renal Injuries." British Journal of Urology 77, no. 4 (April 1996): 512-17.

16. London, Jason A., Lisa Parry, Joseph Galante, and Felix Battistella. "Safety of Early Mobilization of Patients with Blunt Solid Organ Injuries.” Archives of Surgery (Chicago, Ill.: 1960) 143, no. 10 (October 2008): 972-76; discussion 977. https://doi.org/10.1001/archsurg.143.10.972.

17. Wang, Eugene, Kenji Inaba, Saskya Byerly, Ranan Mendelsberg, Jack Sava, Elizabeth Benjamin, Lydia Lam, and Demetrios Demetriades. "Safety of Early Ambulation Following Blunt Abdominal Solid Organ Injury: A Prospective Observational Study." The American 
Journal of Surgery 214, no. 3 (September 1, 2017): 402-6.

https://doi.org/10.1016/j.amjsurg.2017.05.014.

18. Dodgion, Christopher M., Ankush Gosain, Andrew Rogers, Shawn D. St. Peter, Peter F. Nichol, and Daniel J. Ostlie. "National Trends in Pediatric Blunt Spleen and Liver Injury Management and Potential Benefits of an Abbreviated Bed Rest Protocol." Journal of Pediatric Surgery 49, no. 6 (June 1, 2014): 1004-8.

https://doi.org/10.1016/j.jpedsurg.2014.01.041.

19. Teichman, Amanda, Dane Scantling, Brendan McCracken, and James Eakins. "Early Mobilization of Patients with Non-Operative Liver and Spleen Injuries Is Safe and Cost Effective.” European Journal of Trauma and Emergency Surgery, December 5, 2017. https://doi.org/10.1007/s00068-017-0864-9.

20. Peyronnet et al. «Early mobilization is safe after renal trauma: A multicenter study » March 2018European Urology Supplements 17(2):e199-e202. DOI: 10.1016/S15699056(18)30983-7

21. Bukur, Marko, Kenji Inaba, Galinos Barmparas, Christian Paquet, Charles Best, Lydia Lam, David Plurad, and Demetrios Demetriades. "Routine Follow-up Imaging of Kidney Injuries May Not Be Justified.” The Journal of Trauma 70, no. 5 (May 2011): 1229-33. https://doi.org/10.1097/TA.0b013e3181e5bb8e.

22. Breen, Kieran J., Paul Sweeney, Patrick J. Nicholson, Eamonn A. Kiely, and M. F. O’Brien. “Adult Blunt Renal Trauma: Routine Follow-up Imaging Is Excessive.” Urology 84, no. 1 (July 1, 2014): 62-67. https://doi.org/10.1016/j.urology.2014.03.013. 


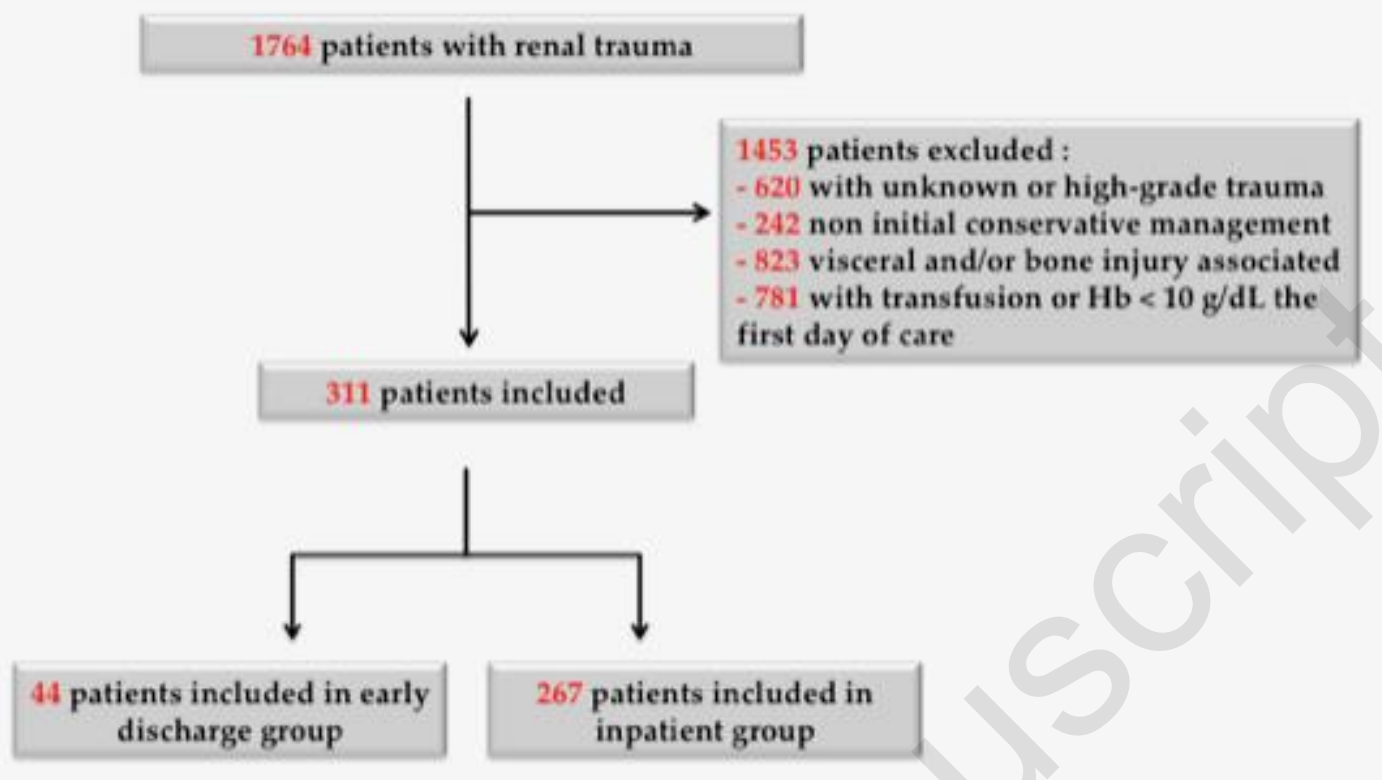

Fig. 1 Flow chart 
|Table 1: patients' characteristics

\begin{tabular}{|c|c|c|c|}
\hline & $\begin{array}{l}\text { Early discharge } \\
\mathrm{N}=44\end{array}$ & $\begin{array}{l}\text { Inpatient } \\
\mathrm{N}=\mathbf{2 6 7}\end{array}$ & $p$-value \\
\hline Median age in years (SD) & $26.6(18.3)$ & $26.8(18.2)$ & 0.620 \\
\hline $\begin{array}{l}\text { Gender } \\
\text { Male } \\
\text { Female }\end{array}$ & $\begin{array}{l}36(81.8 \%) \\
8(18.2 \%)\end{array}$ & $\begin{array}{l}227(85 \%) \\
40(15 \%)\end{array}$ & 0.65 \\
\hline $\begin{array}{l}\text { AAST injury scale } \\
\text { Grade 1: } 108(34.7 \%) \\
\text { Grade 2: } 86(27.7 \%) \\
\text { Grade 3: } 117(37.6 \%)\end{array}$ & $\begin{array}{l}31(70.5 \%) \\
11(25.0 \%) \\
2(4.6 \%)\end{array}$ & $\begin{array}{l}77(28.8 \%) \\
75(28.1 \%) \\
115(43.1 \%)\end{array}$ & $<0.0001^{*}$ \\
\hline $\begin{array}{l}\text { Active bleeding on initial CT } \\
\text { ( } 99 \text { missing values) }\end{array}$ & $0(0 \%)$ & $8(4.3 \%)$ & 0.60 \\
\hline $\begin{array}{l}\text { Angio-embolization for } \\
\text { active bleeding on initial } \\
\text { imaging } \\
\text { (251 missing values) }\end{array}$ & $0(0 \%)$ & $0(0 \%)$ & 0.99 \\
\hline $\begin{array}{l}\text { Initial haemodynamic } \\
\text { instability ( } \mathrm{SBP}<90 \mathrm{mmHg} \text { ) } \\
\text { ( } 2 \text { missing values) }\end{array}$ & $0(0 \%)$ & $3(1.1 \%)$ & 1.00 \\
\hline $\begin{array}{l}\text { Gross haematuria at initial } \\
\text { presentation } \\
\text { (1 missing value) }\end{array}$ & $33(75 \%)$ & $189(71 \%)$ & 0.72 \\
\hline $\begin{array}{l}\text { Re-imaging } \\
\text { (99 missing values) }\end{array}$ & $12(44.4 \%)$ & $165(89.2 \%)$ & $<0.0001^{*}$ \\
\hline $\begin{array}{l}\text { Length of stay } \\
\text { Median (days) } \\
\text { Min-max (days) }\end{array}$ & $\begin{array}{l}2 \\
0-2\end{array}$ & $\begin{array}{l}6 \\
3-257\end{array}$ & $<0.0001^{*}$ \\
\hline $\begin{array}{l}\text { Median follow-up [Q1-Q3] } \\
\text { (min - max; days) } \\
\text { (107 missing values) }\end{array}$ & $\begin{array}{l}44[2-364] \\
(1-4466)\end{array}$ & $\begin{array}{l}89[39-526] \\
(3-3898)\end{array}$ & 0.52 \\
\hline
\end{tabular}

SD: Standard Deviation SBP: Systolic Blood Pressure Q: Quartile 
Table 2 comparison of outcomes in both groups

\begin{tabular}{|c|c|c|c|c|}
\hline & $\begin{array}{l}\text { Early discharge } \\
N=44\end{array}$ & $\begin{array}{l}\text { Inpatient } \\
N=267\end{array}$ & $\begin{array}{l}p \text { value for unadjusted } \\
\text { comparison }\end{array}$ & $\begin{array}{l}\text { Propensity-score weighted } \\
\text { risk difference }\end{array}$ \\
\hline \multicolumn{5}{|l|}{ Primary outcome } \\
\hline $\begin{array}{l}\text { Intervention (interventional radiology } \\
\text { or surgical procedure) } \\
91 \text { missing values }\end{array}$ & $\begin{array}{l}1(3.7 \%) \\
16 \text { missing values }\end{array}$ & $\begin{array}{l}10(5.2 \%) \\
75 \text { missing values }\end{array}$ & 0.99 & $-2.8 \%[-9.3 \%$ to $+3.7 \%]$ \\
\hline \multicolumn{5}{|l|}{ Secondary outcome } \\
\hline $\begin{array}{l}\text { Readmission } \\
93 \text { missing values }\end{array}$ & $1(3.7 \%)$ & $5(2.6 \%)$ & 0.75 & NA \\
\hline $\begin{array}{l}\text { Death from trauma } \\
89 \text { missing values }\end{array}$ & $0(0 \%)$ & $1(0.5 \%)$ & 0.99 & NA \\
\hline $\begin{array}{l}\text { Nephrectomy (radical or partial) } \\
310 \text { missing values }\end{array}$ & $0(0 \%)$ & $0(0 \%)$ & NA & NA \\
\hline $\begin{array}{l}\text { Blood Transfusion } \\
91 \text { missing values }\end{array}$ & $0(0 \%)$ & $0(0 \%)$ & NA & NA \\
\hline
\end{tabular}

NA not applicable 